\title{
The comparison of mindfulness techniques teaching effects on improving teachers' occupational and students' academic performance
}

\author{
Fereshteh Allipour ${ }^{1 \bowtie 凶}$ and Vida Andishmand ${ }^{2}$ \\ ${ }^{1} \mathrm{MSc}$, Iran \\ ${ }^{2} \mathrm{PhD}$, Iran \\ Email: fereshtehallipour@gmail.com
}

\section{ABSTRACT}

The purpose of this study was to compare the effectiveness of Mindfulness Training on teachers' job performance and academic performance of students. The present study was a pre-test and post-test design with control groups. The statistical population of the study consisted of all students and teachers of Shahid Mahdavi's sophomore non-governmental elementary school in Kerman province in the academic year 1397-1398. Using random sampling method, 40 teachers from all bases and 40 students were randomly selected and the subjects of both groups were randomly divided into two experimental and control groups (each group, 20 students and teachers). Subsequently, awareness sessions were conducted on them. After completing the training, they were re-tested. The tool used in this research was the teacher-occupation performance questionnaire 2010 and Pham and Tyler's (1999) academic performance questionnaire. Data were analyzed using SPSS-24 software and covariance analysis. The results showed a significant improvement in the teachers' job performance scores and the academic performance of the students in the experimental group compared with the control group at the level of $p$ <0.05). The present study showed that mindfulness education can help to improve the occupational and academic performance of teachers and students groups. From the tables and the results of the research hypotheses, it is concluded that Mindfulness training in occupational performance has not been affected by the function of task performance. Mindfulness education has been more influential on the underlying performance and further increased. Mindfulness education in academic performance exerts much emotional impact but it has not influenced planning. The impact on moderate motivation will slightly increase self-efficacy, but little impact on the lack of outcome control. And finally, the result of the covariance analysis revealed that teaching mindfulness techniques had been more effective on teachers' occupational performance than students' academic improvement.
Original Article

PII: S232247702000002-10

Rec. O4 January, 2020

Acc. 20 March, 2020

Pub. 25 March, 2020

\section{Keywords}

Mindfulness techniques,

Academic performance of

students,

Teachers' occupational

performance

\section{INTRODUCTION}

Teachers, as human forces are among the most important factors of education. These factors drive the wheels of the organization so that it moves forward. It is obvious that if the organization can provide the appropriate conditions for them, they can be expected to have a geart performance. Teachers are identified as the most important and effective factors in the school and are responsible for their job (Baldauf and Cravens, 2002). Job performance is in fact the amount of efficiency achieved by the person in the organization including service and manufacturing functions and is affected by two factors which are the ability of employees to perform job duties and the existence of motivation among the employees, since, if they have the required abilities and motivations, they will do their works appropriately (Mohammadi 2011; Arab Faizabadi et al.
2014). Performance can be divided into two groups' of functional performance and underlying performance. A part of the performance that is usually present in the formal job description is called functional performance. The underlying function is defined as the behavior that contributes to the effectiveness of the organization through the impact on the psychological, social and organizational fields of work (Motowidlo 2003, quoted by Khorsandifard, et al. 2016). On the other hand, educational performance is influenced by the various biological, psychological and social dimensions. Various factors affect the academic performance of individuals, which According to education professionals, are divided into individual, academic, family, and social factors (Zahrakar, 2005).

The amount of academic Achievement that is measured using different course tests is called the academic performance (Seif, 2013). Educational performance is one of the important indicators in the 
assessment of students, using evaluation of academic scores and educational achievement as a criterion for assessment and selection of people in their occupation and education (Hashemian, 2013). According to Pham and Taylor (1999) academic performance has five components. Self - efficacy, a sense of confidence and the ability to respond to educational requirements and activities. Emotional effects, an individual's response to a set of emotions such as anxiety that excites the individual. Planning is the ability to organize courses timetable according to a specific and measurable basis and also to manage time to perform educational tasks. The absence of outcome control is due to believing that more individual does not lead to a desired outcome. Motivation is the self - motivation for studying more and academic motivation to achieve higher marks, to get a suitable job or just study to gain knowledge and improve the public skills and knowledge. It seems that" mindfulness "'" is one of the variables that can affect teachers ' job performance and academic performance of students.

In recent years, the use of mindfulness training programs for teachers and students is increasing. The purpose of these programs is to enhance emotional control (Floko Goldberg 2015; Maloney, 2016) and to improve social relations (Kohilo Ostrik, 2016) and is related to an extended range of cognitive, emotional and health factors (brown, cresol, ryan, shadowing) (Brownet al., 2015). This kind of training has a great emphasis on learning through direct experience (Lu et al., 2017). Mindfulness means paying attention in a specific and purposeful way in present without any judgment. It's a kind of consciousness without judgment, that is indescribable and according to present time and based on a special experience I'd someone in a special moment. Moreover, this concept refers to confession of an experience and accepting it (Lu et al., 2017). The most common definition of mindfulness is presented by Kabat Zin (2003). He defines it as consciousness about events which happen now and here, inside and outside us without any preconceived conclusions, and without following a certain Result."

The seven essential elements of mindfulness are:

1. Not judging,

2. Being patient,

3. Having an open mind,

4. Trusting,
5. Valuing the present moment instead of getting busy doing something.

6. Accepting the life facts at any moment,

7. Independence and abandoning (Kabat-Zinn, 2005).

Mindfulness based medical recognition requires specific behavioral, cognitive and strategies to focus on attention process, which in turn leads to the prevention of bad temper " negative thinking, tendency to disturbing responses and growth of new pleasant thoughts and emotions (Spinhoven et al., 2017). This tutorial seeks to realize three fundamental goals which are setting attention, creating awareness, decentralization, and creating acceptance of present states and mental states.

This therapy is taught to educate people to be more aware and behave properly with their thoughts and feelings. It also helps individuals to look at all the stimuli that are placed in their consciousness at any moment without judging and yet with Attention (Day and Thorn, 2017). mindfulness includes various exercises, such as eating raisins, (eating mindful), body scan, breathing, exercise of breathing space, practice of walking with the presence of mind and a few therapeutic practices that reveal the connection between the manner, thoughts, emotion, and physical sensations. All of these exercises forms a kind of attention to the physical and surrounding situations in the present moment and reduce the automatic processes of thoughts (Kaviani et al., 2008). Schools often justify the use of training programs because it promotes positive behaviour and improves student's educational performance, and therefore it seems to be effective directly and indirectly on students as well (Britton, 2015).

Teachers will be more likely to pay attention by performing mindfulness exercises. Certainly, their ability of teaching and communicating will be promoted and gets more influential on students. Therefore, if the training exercises are used by teachers in the classroom, the attention and focus of the students will be higher in the classroom, their tension and anxiety decreases and their academic performance will improve (Napoli, 2013). On the other hand, the reason of many students ' education problems is their lack of attention in the classroom and during the study. In fact, many of the students have a physical presence in the classroom, but they do 
not have attention when the teacher teaches so they face many problems. Therefore, if teachers learn their training exercises properly and practice them properly in class, they will be able to improve the quality of teaching and help the students (Brown and Oslan, 2015). In a study, King and Harris (2017) concluded that there is a significant relationship between mindfulness and employees' job satisfaction and employees' performance (Reb, 2018). In a research entitled as managers' mindfulness and employees' performance, mentioned a mediator between interpersonal justice and employees' stress. The results showed that there is a positive and significant relationship between mindfulness and job performance.

The results of the researches by Tuckeyet al. (2018), entitled as, "is there a relationship between mindfulness and job management, and job satisfaction of employees, "showed that mindfulness is related to job satisfaction. Mettler et al. (2017), revealed in their research entitled as concentrated mindfulness and coping with university, that mindfulness is obviously related to all kinds of coping such as educational, personal and emotional.

Mesmer-Magnus et al., (2017) also had a research as mindfulness characteristics in job, a meta-analysis of personal and professional relationships of positive characteristics, and found that mindfulness has relationship with confidence, mental health, and satisfaction of job and life. Puriarizi et al. (20187), also found in a research as the effect of mindfulness on educational improvement and Compatibility , that mindfulness has a direct and significant relationship with academic progress and educational harmony . Afshari and Fathi (2018), also studied the relation between the sense of solidarity and job satisfaction with the role of the mediator of emotional intelligence, and found that there is a positive and meaningful relationship between mindfulness and job satisfaction. Additionally, Zarei and Arshad Hosseini (2018), found that there is a significant difference in occupational stress and job - efficacy of physical education instructors and there is a significant difference between the scores of two groups of test and evidence in occupational stress and occupational self - efficacy . According to the importance of teachers and students role in the development of societies and due to the fact that in any period of history and according to the social needs in each period, there are psychologists, sociologists, and experts to help teachers and students to improve their performance; the purpose of this study is to study the effectiveness of therapeutic effectiveness of mindfulness on improving the job performance of teachers and students ' education performance.

\section{METHODOLOGY}

This study was a semi - experimental study with pre test, post - test and - using a control group. The population of this study consisted of all the students and teachers of Shahid Mahdavi elementary school in Kerman during the academic year of 2010 - 2011. The students were randomly divided into two groups: experimental and control groups. The subjects were randomly divided into two experimental and control groups.

\section{Data collection tools \\ Teachers ' job performance questionnaire, (Darandeh 2010)}

The teachers 'job performance questionnaire, (Darandeh 2010), included 105 questions that examined the job performance of teachers in both field performance and functional performance This questionnaire is graded in 5 - point Likert Scale from very low (1) to very high scores (5). teachers ' scores of 27 to 45 showed teachers ' low performance, the scores of 45 to 90 showed teachers ' mediate performance and scores higher than 90 showed ' high performance of teachers .

The scores range between 27 to 135. Higher scores indicate better job performance. By implementing this questionnaire in the pilot study with the population of 106 persons, Shariatmadari and Darandeh measured the reliability of the questionnaire which was calculated through internal consistency and cronbach's alpha method. The reliability was calculated by cronbach's alpha which was 0.92. In the present study, the reliability of the questionnaire was determined through cronbach "s alpha which was 69.0 for the whole questionnaire, 77.0 for underlying performance and 74.0 for functional performance and shows a desirable reliability of this questionnaire for the present study 


\section{Educational performance of Fam andTyler (EPT)}

Educational performance of Fam and Tyler (EPT) 1999 was created and standardized by Dortaj for Iran Society. The questionnaire includes 48 questions that measure five academic fields: self-efficacy, emotional effects planning, lack of outcome control and motivation. A score is devoted to each of these five factors, respectively $5,4,3,2,1$. a score of less than 53 indicate poor self- efficacy and efficacy and a score of higher than 85 shows high self-efficacy. The score below 28 shows weak emotional effects and a higher than 53 score indicates strong emotional .effects The score below 6 indicates strong outcomes control. A score below 14 shows a strong motivation.

The score below 120 indicates poor educational performance and higher than 175 shows a strong academic performance. A score between 121 and 174 indicates the average academic performance. In the present study alpha Cranach was used to determine the reliability of the questionnaire in which the values for the subscales were respectively $0.70,0.69,0.65$, $0.75,0.77$ and for the whole questionnaire was 0.77 that shows the desired reliability of this questionnaire in this sample.

\section{The training package of mindfulness techniques for students and teachers \\ Mindfulness based training program for teachers}

The first session: Introduction of mindfulness theoretical foundations, conceptualization, and the necessity of mindfulness, was taught using the raisin and body scans techniques.

The second session: the concept of stress, judgment, anger, depression, and practice of diaphragm breathing was taught.

The third session: providing the subjects in the field of emotional regulation skills, resilience, self solving and positive thinking skills, in this session (sitting meditation) and body scan with yoga .was taught.

The fourth session: the basic skills of interpersonal communication, anger, the skill of selfexpression, and the rules of protest were presented and Exercise of meditation (mindful walking) was taught'.

The fifth session: The concepts in the field of negative emotional tolerance skills and the emotional experience of anger were presented. This week the body scan practice was stopped and the exercise of sitting and focusing on the breathing began, so that respiration was used as a practice to control attention."

Sixth meeting: The concepts of strengthening love and friendship, promoting health and love for yourself and others were discussed. This session exercises were like the fifth session of practicing, including sitting meditation training and practice of breathing and a revision of home assignment and recording of pleasing events. Finally, at this session, the technique of raisins was taught related to how to eat properly.

The seventh session: In this week, people generally use techniques of sitting meditation, yoga, and body scanning. After training, the teachers must use a combination of all the three techniques.

The eighth session: This week, the teachers are asked to choose the technique that fits their status best. They may just choose to sit mindfully or do yoga or a scan of the body, or two or three of the techniques or more. What matters is that they use these experiences and techniques at the end of education and apply it throughout their lives (Kabat Zinn, 2005). A short discussion of the obstacles in applying the methods, reviewing the literature discussed in the previous sessions, and finally the conclusion and conducting the post test.

\section{Mindfulness based training program for students}

The first session: a brief introduction of mindfulness training, reviewing the performance of the autopilot and the difference with mindfulness function, the training of mindful breathing by two methods of teddy bear and breathing with a pinwheel and playing wind and cloud game.

The second session: mindful Breathing with pinwheel, concentration on the tasting, exercise of mindfulness, referring to the difference between characterization and judgment and the performance of seed and butterfly game.

The third session: Playing with the bear, training three concepts of emotions, physical senses and thoughts.

The Fourth session: 3 - minute mindful Breathing training, water glass exercise, playing the invisible ball game, and training bubble meditation. 
The fifth session : Playing with the bear , focusing attention on hearing, mindful listening training (the receiver sound) and playing cat and cow games (making mirrors).

The sixth session: training mindful breathing with flowers and candles, focusing on hearing senses, mindful listening, body scans training, and playing the jump game.

The seventh session: mindful breathing (threeminute breathing), focusing on the sense of sight, mindful viewing training, the first part (drawing), training the distinction between judging and describing by examining an object from different angles and playing the curious mind game.

The eighth session: conscious breathing with teddy bear, focus and attention on vision, training of mindful sight, second part (drawing), examining perceptual errors, performing love kindness meditation, and performing memory game.

The ninth session: mindful Breathing (3 minutes Breathing), focusing the attention on the sense of touch, learning of mindful touch, exercising to distinguish the difference between judgment and description by examining a few objects with different roughness and softness degrees, and the game of sun and ice cream.

The 1oth session: mindful Breathing (Breathing 3 minutes), focusing attention on the sense of smell, the mindful smell training, practicing bubble meditation, and the applying the two exercises of mountain state practices and child status.

The eleventh session: mindful breathing (3 minutes breathing), an awareness of the body moving, taking steps mindfully, and practicing a pendulum movement.

The 12th session: mindful breathing (3 minutes breathing), a review of the overall mindful drills which were presented and examining the applicability of mindfulness to the routine life.

And finally, the conclusion and the implementation of the post test. In this study, in addition to the use of descriptive statistics, such as average and standard deviation and variance, the covariance analysis is used to investigate the hypotheses of the research.

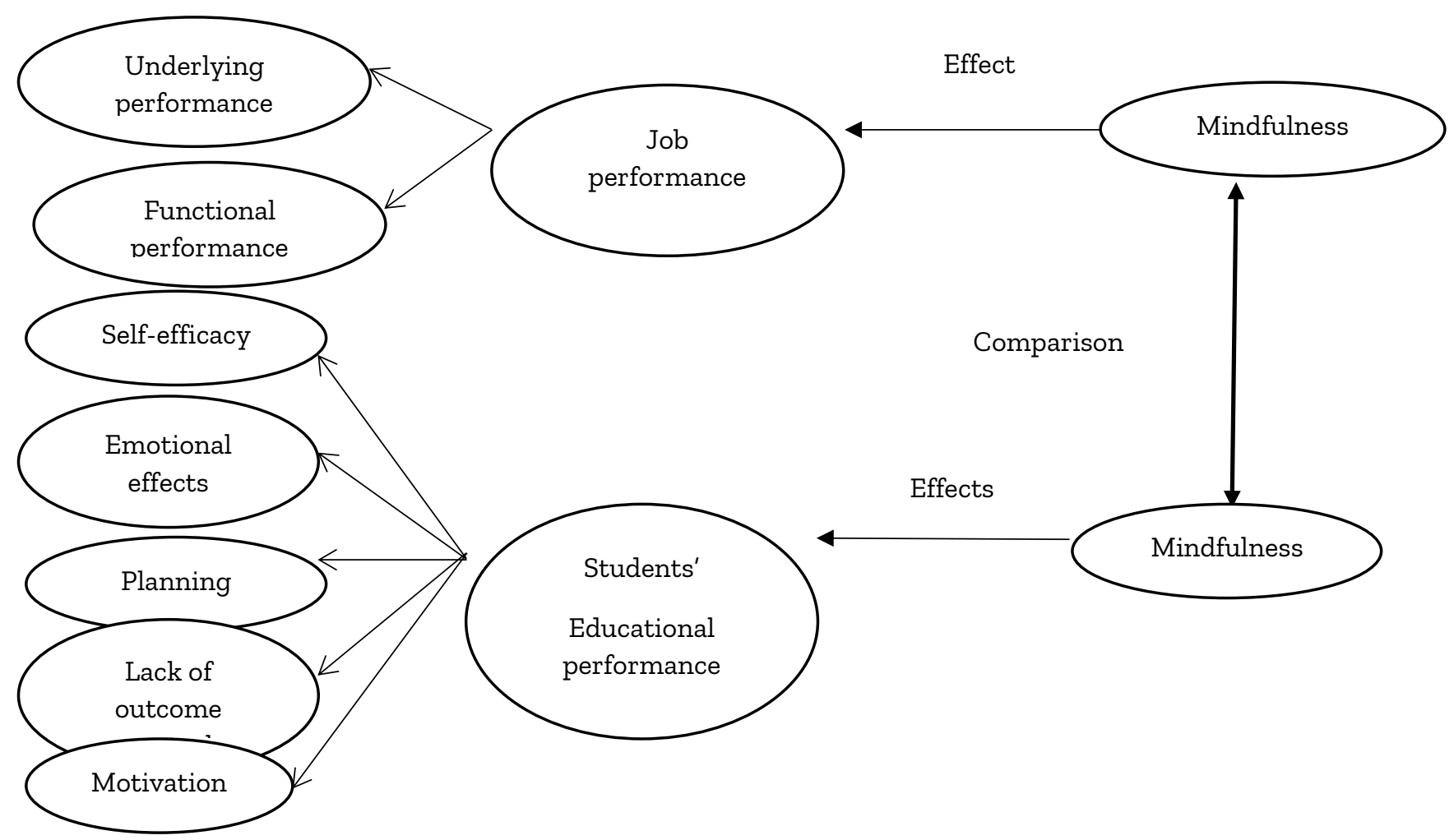

Figure 1. Mindfulness based training program 
Figure 2. Analytical model of mindfulness techniques

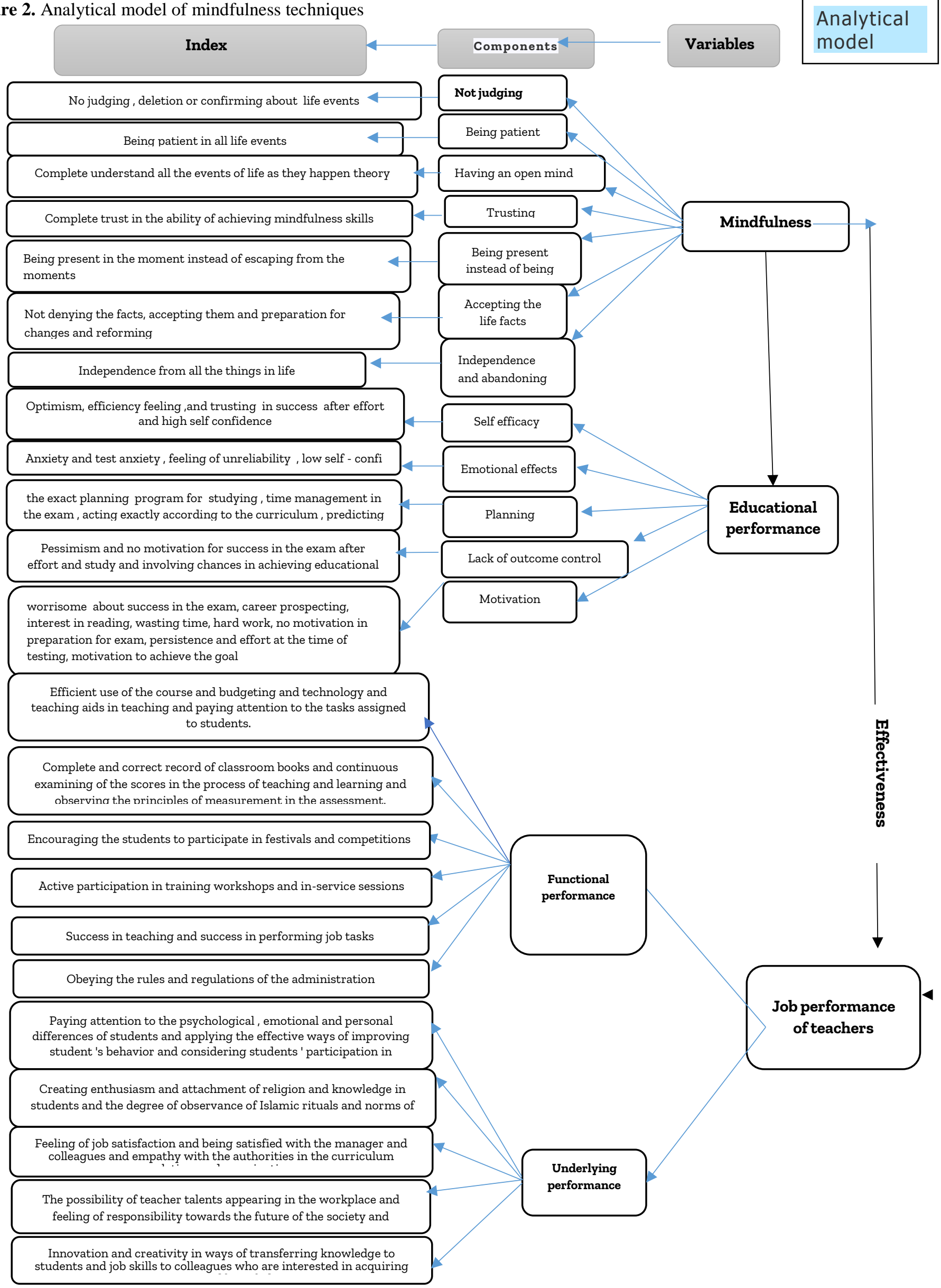




\section{FINDINGS}

In this section we will first examine the demographic and descriptive aspects of the research variables and then investigate the use of parametric tests and then investigate the research hypotheses.

Table 1. Descriptive indexes of job performance and its sub-components before and after the experimental intervention.

\begin{tabular}{|c|c|c|c|c|c|c|c|}
\hline 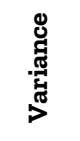 & 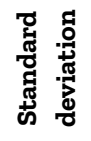 & 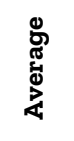 & 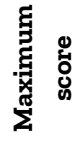 & 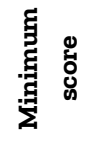 & 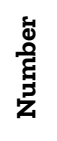 & & 总 \\
\hline 0.323 & 0.447 & 4.40 & 114 & 27 & 20 & $\begin{array}{l}\text { Pre } \\
\text { test }\end{array}$ & \multirow{2}{*}{$\begin{array}{c}\text { Job } \\
\text { performance }\end{array}$} \\
\hline 0.367 & 0.472 & 4.84 & 135 & 27 & 20 & $\begin{array}{l}\text { Post } \\
\text { test }\end{array}$ & \\
\hline 0.312 & 0.566 & 4.45 & 66 & 14 & 20 & $\begin{array}{l}\text { Pre } \\
\text { test }\end{array}$ & \multirow{2}{*}{ Functional } \\
\hline 0.312 & 0.567 & 4.45 & 70 & 14 & 20 & $\begin{array}{l}\text { Post } \\
\text { test }\end{array}$ & \\
\hline 0.325 & 0.445 & 4.24 & 48 & 13 & 20 & $\begin{array}{l}\text { Pre } \\
\text { test }\end{array}$ & \multirow{2}{*}{ Underlying } \\
\hline 0.410 & 0.662 & 4.90 & 65 & 13 & 20 & $\begin{array}{l}\text { Post } \\
\text { test }\end{array}$ & \\
\hline
\end{tabular}

Table 2. Description of educational performance index and its sub - components in two groups before and after the experimental intervention

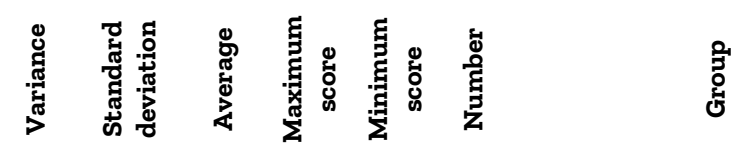

\begin{tabular}{|c|c|c|c|c|c|c|c|}
\hline 0.300 & 0.440 & 2.722 & 134 & 120 & 20 & Pre test & \multirow{2}{*}{$\begin{array}{l}\text { Educational } \\
\text { performance }\end{array}$} \\
\hline 0.330 & 0.479 & 4.122 & 175 & 120 & 20 & post test & \\
\hline 0.314 & 0.552 & 3.009 & 65 & 53 & 20 & Pre test & \multirow{2}{*}{ Self-efficacy } \\
\hline 0.320 & 0.576 & 3.195 & 85 & 53 & 20 & post test & \\
\hline 0.344 & 0.442 & 2.609 & 47 & 28 & 20 & Pre test & \multirow{2}{*}{$\begin{array}{l}\text { Emotional } \\
\text { effects }\end{array}$} \\
\hline 0.428 & 0.540 & 4.900 & 53 & 28 & 20 & post test & \\
\hline 0.312 & 0.450 & 1.590 & 17 & 11 & 20 & Pre test & \multirow{2}{*}{ Planning } \\
\hline 0.312 & 0.451 & 1.590 & 23 & 11 & 20 & post test & \\
\hline 0.304 & 0.552 & 3.009 & 9 & 6 & 20 & Pre test & \multirow{2}{*}{$\begin{array}{c}\text { Lack of } \\
\text { outcome } \\
\text { control }\end{array}$} \\
\hline 0.307 & 0.556 & 3.012 & 13 & 6 & 20 & post test & \\
\hline 0.350 & 0.450 & 3.503 & 17 & 14 & 20 & Pre test & \multirow{2}{*}{ Motivation } \\
\hline 0.369 & 0.479 & 4.789 & 24 & 14 & 20 & post test & \\
\hline
\end{tabular}

Before testing the hypotheses of this research, the normalcy of the variables must be ensured that the Kolmogorov Smirnoff Test and Shapiro-Wilk W-test were used to investigate the variables normalcy. According to table 3 the results indicate that the assumption of normalcy for all research variables is confirmed because the significance level is equal to or greater than 0.05 .

According to Table 4, scores of people were used in the pre - intervention implementation in this analysis. The test results $(F=107.900, P=0.003)$ indicate the effect of learning mindfulness on job performance.

Table 3. The results of Kolmogorov Smirnoff Test and Shapiro-Wilk W-test to investigate the assumption of normalcy.

\begin{tabular}{|c|c|c|c|c|c|c|}
\hline \multicolumn{3}{|c|}{$\begin{array}{l}\text { Shapiro-Wilk } \\
\text { W-test }\end{array}$} & \multicolumn{3}{|c|}{$\begin{array}{c}\text { Kolmogorov } \\
\text { Smirnoff Test }\end{array}$} & \\
\hline 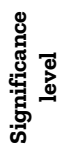 & 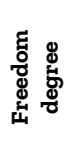 & 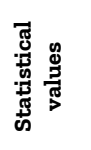 & 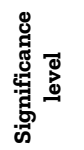 & 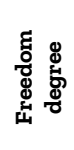 & 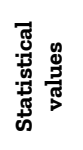 & \\
\hline 150. & 39 & 885. & *200. & 39 & 147. & $\begin{array}{l}\text { Job performance } \\
\text { Pre test }\end{array}$ \\
\hline 164. & 39 & 998. & 230. & 39 & 198. & $\begin{array}{l}\text { Job performance } \\
\text { Post test }\end{array}$ \\
\hline 152. & 39 & 809. & ${ }^{*} 213$. & 39 & 113. & $\begin{array}{c}\text { Functional performance } \\
\text { pre test }\end{array}$ \\
\hline 152. & 39 & 809. & 213. & 39 & 113. & $\begin{array}{c}\text { Functional performance } \\
\text { post test }\end{array}$ \\
\hline 150. & 39 & 565. & ${ }^{*} 250$. & 39 & 014. & $\begin{array}{l}\text { Underlying performance } \\
\text { pre test }\end{array}$ \\
\hline 169. & 39 & 663. & 277. & 39 & 029. & $\begin{array}{l}\text { Underlying performance } \\
\text { post test }\end{array}$ \\
\hline 162. & 39 & 658. & ${ }^{*} 240$. & 39 & 077. & $\begin{array}{c}\text { Educational performance } \\
\text { pre test }\end{array}$ \\
\hline 176. & 39 & 710. & 263. & 39 & 122. & $\begin{array}{c}\text { Educational performance } \\
\text { post test }\end{array}$ \\
\hline 150. & 39 & 885. & ${ }^{*} 200$. & 39 & 147. & Self-efficacy pre test \\
\hline 157. & 39 & 900. & 210. & 39 & 159. & Self-efficacy post test \\
\hline 258. & 39 & 285 . & *230. & 39 & 146. & Emotional effects pre test \\
\hline 320. & 39 & 663. & 310. & 39 & 190. & Emotional effects post test \\
\hline 152. & 39 & 540. & ${ }^{*} 118$. & 39 & 146. & Planning pre test \\
\hline 152. & 39 & 541. & 118. & 39 & 146. & Planning post test \\
\hline 150. & 39 & 885. & $*_{145}$ & 39 & 128. & $\begin{array}{c}\text { Lack of outcome control } \\
\text { pre test }\end{array}$ \\
\hline 152. & 39 & 890. & 147. & 39 & 130. & $\begin{array}{c}\text { Lack of outcome control } \\
\text { post test }\end{array}$ \\
\hline 112. & 39 & 445. & *244. & 39 & 112. & Motivation pre test \\
\hline 118. & 39 & 759. & 287. & 39 & 117. & Motivation post test \\
\hline
\end{tabular}

Table 4. Covariance test to investigate the mindfulness training effects on job performance

\begin{tabular}{|c|c|c|c|c|c|c|}
\hline 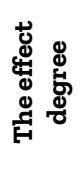 & 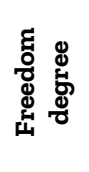 & 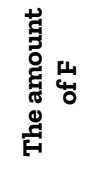 & 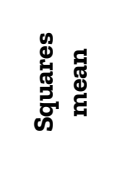 & 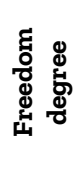 & 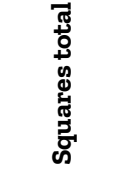 & 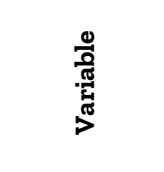 \\
\hline 0.590 & 0.001 & 80.509 & 17761.568 & 1 & 17761.568 & $\begin{array}{c}\text { Job } \\
\text { performance }\end{array}$ \\
\hline 0.588 & 0.003 & 107.900 & 2333.610 & 1 & 2333.610 & Group \\
\hline
\end{tabular}


According to table 5, scores of people were used in the pre - intervention implementation in this analysis. The test results $(\mathrm{F}=80.600 \mathrm{P}=0.000)$ indicate the effect of learning mindfulness on functional performance

According to table 6, scores of people were used in the pre - intervention implementation in this analysis. The test results $(\mathrm{F}=129.439 \mathrm{P}=0.004)$ indicate the effect of learning mindfulness on underlying performance.

According to table 7, scores of people were used in the pre - intervention implementation in this analysis. The test results $(\mathrm{F}=105.900 \mathrm{P}=0.003$ ) indicate the effect of learning mindfulness on educational performance.

According to table 8, scores of people were used in the pre - intervention implementation in this analysis. The test results $(F=90.207 \mathrm{P}=0.002)$ indicate the effect of learning mindfulness on self-efficacy.

According to table 9, scores of people were used in the pre - intervention implementation in this analysis. The test results $(F=985.236 \mathrm{P}=0.003$ ) indicate the effect of learning mindfulness on emotional effects.

According to table 10, scores of people were used in the pre - intervention implementation in this analysis. The test results $(\mathrm{F}=80.509 \mathrm{P}=0.00)$ indicate the effect of learning mindfulness on planning.

According to table 11, scores of people were used in the pre - intervention implementation in this analysis. The test results $(F=112.700 \mathrm{P}=0.004)$ indicate the effect of learning mindfulness on lack of outcome control.

According to table 12, scores of people were used in the pre - intervention implementation in this analysis. The test results $(F=102.300, P=0.005)$ indicate the effect of learning mindfulness on motivation.

The results of table 13 show that considering the pre test scores as covariance variables, mindfulness training intervention has resulted in significant differences between the two groups in their job performance. The intervention degree was $(F=10.21$, $\mathrm{P}<0.001, \mathrm{H} 2=0,50)$, so we can say that mindfulness causes an improvement in job performance.

The results of table 14 show that considering the pre test scores as covariance variables, mindfulness training intervention has resulted in significant differences between the two groups in their educational performance. The intervention degree was $(F=0.001, P<10.65, \mathrm{H} 2=0)$, so we can say that mindfulness causes an improvement in educational performance.
Table 5. Covariance test to investigate the effects of mindfulness training on functional performance

\begin{tabular}{|c|c|c|c|c|c|c|}
\hline 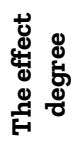 & 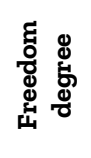 & 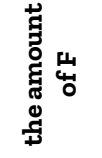 & 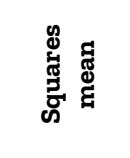 & 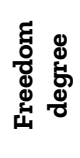 & 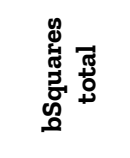 & $\begin{array}{l}\stackrel{0}{0} \\
\frac{0}{\pi} \\
\stackrel{\pi}{\pi} \\
> \\
>\end{array}$ \\
\hline 0.599 & 0.001 & 80.509 & 17761.568 & 1 & 17761.568 & $\begin{array}{l}\text { Functional } \\
\text { performance }\end{array}$ \\
\hline 0.599 & 0.000 & 80.600 & 2333.610 & 1 & 2333.610 & Group \\
\hline
\end{tabular}

Table 6. Covariance test to investigate the effects of mindfulness training on underlying performance

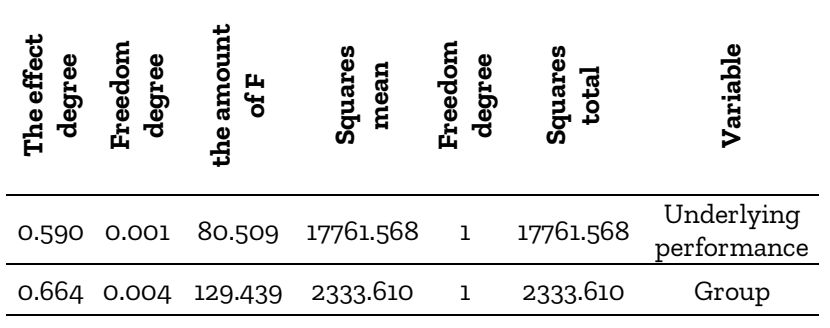

Table 7. Covariance test to investigate the effects of mindfulness training on educational performance

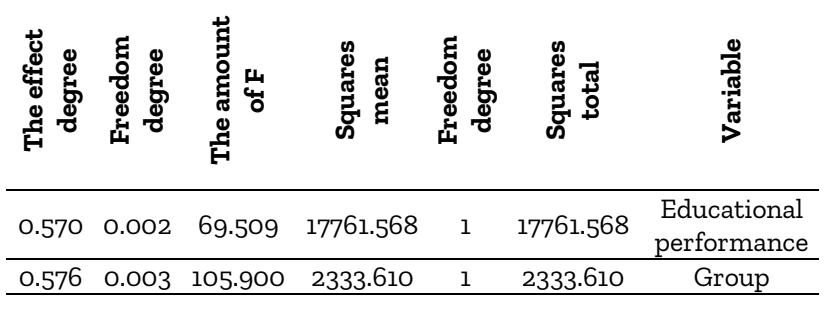

Table 8. Covariance test to investigate the effects of mindfulness training on self-efficacy

\begin{tabular}{|c|c|c|c|c|c|c|}
\hline 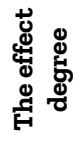 & 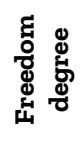 & 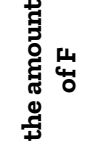 & 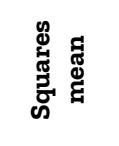 & 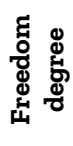 & 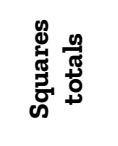 & $\stackrel{0}{\stackrel{0}{0}}$ \\
\hline 0.595 & 0.001 & 80.509 & 1761.568 & 1 & 1761.568 & $\begin{array}{c}\text { Self- } \\
\text { efficacy }\end{array}$ \\
\hline 0.600 & 0.002 & 90.207 & 2423.610 & 1 & 2423.610 & Group \\
\hline
\end{tabular}

Table 9. Covariance test to investigate the effects of mindfulness training on emotional effects

\begin{tabular}{|c|c|c|c|c|c|c|}
\hline 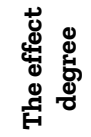 & 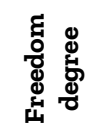 & 壱 & 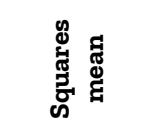 & 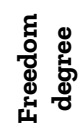 & 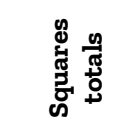 & 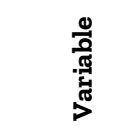 \\
\hline 0.599 & 0.002 & 670.980 & 14450.998 & 1 & 14450.998 & $\begin{array}{l}\text { Emotional } \\
\text { effects }\end{array}$ \\
\hline 0.697 & 0.003 & 985.236 & 7650.09 & 1 & 7650.09 & Group \\
\hline
\end{tabular}


Table 10. Covariance test to investigate the effects of mindfulness training on planning

\begin{tabular}{|c|c|c|c|c|c|c|}
\hline 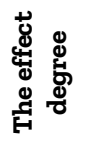 & 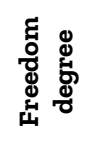 & 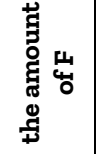 & 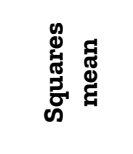 & 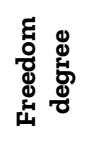 & 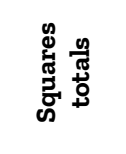 & 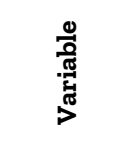 \\
\hline 0.593 & 0.000 & 80.509 & 17761.560 & 1 & 17761.560 & Planning \\
\hline 0.593 & 0.000 & 80.509 & 2333.630 & 1 & 2333.630 & Group \\
\hline
\end{tabular}

Table 11. Covariance test to investigate the effects of mindfulness training on lack of outcome control

\begin{tabular}{|c|c|c|c|c|c|c|}
\hline 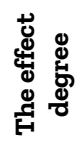 & 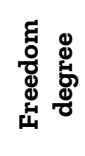 & 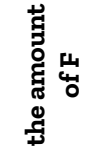 & 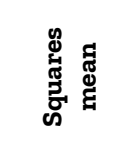 & 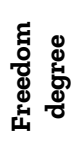 & 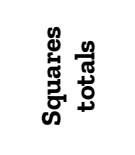 & $\begin{array}{l}\stackrel{0}{\pi} \\
\stackrel{0}{\pi} \\
\stackrel{\pi}{\pi} \\
>\end{array}$ \\
\hline 0.570 & 0.001 & 80.509 & 16561.844 & 1 & 16561.844 & $\begin{array}{c}\text { Lack of } \\
\text { outcome } \\
\text { control }\end{array}$ \\
\hline 0.576 & 0.004 & 112.700 & 2063.500 & 1 & 2063.500 & Group \\
\hline
\end{tabular}

Table 12. Covariance test to investigate the effects of mindfulness training on motivation

\begin{tabular}{|c|c|c|c|c|c|c|}
\hline 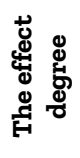 & 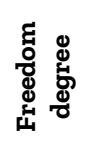 & 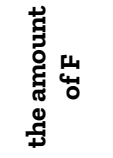 & 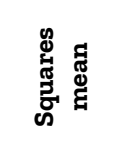 & 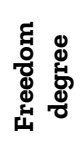 & 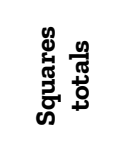 & 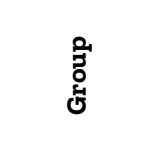 \\
\hline 0.570 & 0.002 & 80.698 & 568.1229 & 1 & 568.1229 & Motivation \\
\hline 0.596 & 0.005 & 102.300 & 610.546 & 1 & 610.546 & Group \\
\hline
\end{tabular}

Table 13. The results of covariance analysis test of one variable for the post test scores of job performance

\begin{tabular}{|c|c|c|c|c|c|c|}
\hline & & & & & $\begin{array}{l}\text { Changes } \\
\text { source }\end{array}$ & \\
\hline 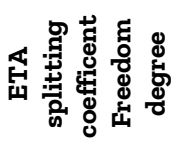 & 山 & 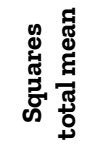 & 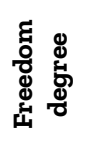 & 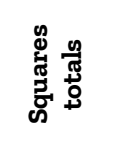 & & 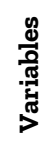 \\
\hline $0.42 \quad 0.001$ & 15.21 & 688.77 & 1 & 688.77 & $\begin{array}{l}\text { Covariance } \\
\text { (post test) }\end{array}$ & $\begin{array}{l}\stackrel{\Xi}{~} \\
\text { ర }\end{array}$ \\
\hline \multirow[t]{3}{*}{$0.50 \quad 0.001$} & 10.21 & 960.55 & 1 & 960.55 & Group & प्⿱艹 \\
\hline & & 45.27 & 37 & 950.80 & Error & \\
\hline & & & 39 & 2600.12 & Total & \\
\hline
\end{tabular}

Table14. The results of covariance analysis test of one variable for the post test scores of educational performance

\begin{tabular}{|c|c|c|c|c|c|c|c|}
\hline \multicolumn{8}{|c|}{$\begin{array}{l}\text { Changes } \\
\text { source }\end{array}$} \\
\hline 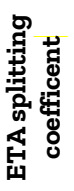 & 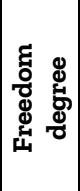 & 山 & 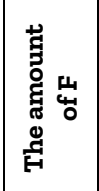 & 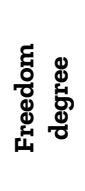 & 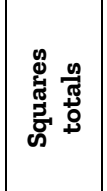 & & 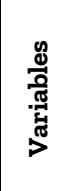 \\
\hline 0.34 & 0.001 & 16.28 & 688.69 & 1 & 688.69 & $\begin{array}{c}\text { Covariance } \\
\text { (pre test) }\end{array}$ & \\
\hline \multirow[t]{3}{*}{0.43} & 0.001 & 10.65 & 960.54 & 1 & 960.54 & Group & 承 \\
\hline & & & 45.25 & 37 & 950.82 & Error & 苟 \\
\hline & & & & 39 & 2599.95 & Total & \\
\hline
\end{tabular}

\section{\# DISCUSSION AND CONCLUSIONS}

Results of the covariance analyses show that there is a difference between the job performance scores of teachers and the student's academic performance by controlling the pre - test scores. Therefore, it can be said that mindfulness improves the job performance of teachers and students ' education performance. This finding is consistent with Afshari and Fathi, (2018), Akbari et al. (2017), Tuckey (2017), Akbari et al. (2018), Akbari et al. (2014), Brandy et.al (2014). In the approval of this finding, it can be stated that the consciousness of consciousness creates its effects through its mechanisms in the individual's vision of its performance. It is thought to be able to engage with informed attention and extend the relevance of more acceptances to the current experience, and instead chooses more useful ways to respond, thus increasing the job performance of teachers. The consciousness with focusing on realities and attention based on this and now as well as rejection or denial of different themes and problems, and in contrast to their experience, reduces Fred's magnification and thereby improving his unhealthy behavior patterns and improving his career performance. This method reduces anxiety, physiological arousal, anxiety, and increased job performance by increasing an individual's awareness of the present - present experiences and turning attention to the more efficient cognitive processing and processing of 
information. With practice, students find the ability to engage themselves consciously and persevere in the face of difficult situations, and be able to remain calm in front of the problems and problems of their school and find a rational solution and that process will improve students ' educational performance.

In the case of this finding, Kabat-Zinn et al. (2007)stated that mindfulness is one of the treatments based on stress reduction and psychotherapy, in which a mental representation of things in life that are out of control of human being at once, is taught through breathing and thinking. Increasing attention and awareness of the thoughts, emotions, and trends are some of the positive aspects of mindfulness, which lead to the co - ordination of the adaptive behaviors and the positive psychological states; it even leads to improving the individual's ability to engage in individual and social activities and their interest in these activities. These trainings, therefore, can change people's attitudes towards accidents and events by improving the mentioned abilities and encouraging them to participate in individual and social activities and be effective in improving their job performance. (Sharf, 2009). Results of the covariance analyses of one way show that there is no difference between the functional performance scores of teachers and groups by controlling the pre - test scores. Therefore, it is possible to say that mindfulness does not improve functional performance. This finding is not consistent with the results of Afshari and Fathi, (2018), Janaabadi, et.al. (2016), Rastgoo et.al (2016), Akbari Amarghan and Amouzegar, (2014), Reb,. (2018). Tuckey et.al (2017) Mesmer, and Magnus et al 2018 researches. In explaining this finding, it can be stated that mindfulness is a cure that uses cognitive skills to increase psychological flexibility. In this approach, cognitive flexibility is the increase in the ability of the clients to communicate with their experiences at present and based on what is possible for them at that moment, in a manner consistent with the underlying values. Izadi, et al., (2014). Mindfulness is based on the hypothesis, that psychological damage is associated with an effort to control or avoid negative thoughts and emotions. Zargar et al. (2012)

In this study, the effectiveness of mindfulness on the functional performance of teachers is not significant, it is likely that one of the causes of this fact is that the functional performance of teachers is known and monitored by the school director or inspectors, and also because of holding periods of service, training workshops and numerous sessions, which are related to direct job functions of teachers and also because of the selections of interviews and entrance exams for which teachers sit in order to get hired , the majority of teachers who are joined to schools have the necessary knowledge in terms of familiarity with the basic tasks of teaching job (teaching, writing plan, assessment of students, seniority, etc.) and hence teachers seem to have done their duty fairly well. Therefore, in this study, after training mindfulness, there has been no change in the teachers ' functional performance because the teachers are always doing it. The results of one-way analysis of covariance show that there is a difference between the scores of the subjects in post - test and control groups. Therefore, it can be said that mindfulness can improve the Underlying performance. In approval of these findings, it can be stated that the mindfulness training allows one to gain the opportunity to become more receptive to others and accept others without undue and negative judgments. It also encourages individuals to be kinder and sensitive to the needs of others (Rastgoo et al. 2016). In fact, by increasing the capacity of people in self - awareness, empathic concern and emotional regulation, there will be some steps to increase teachers ' capacity and improve their underlying performance.

Results of the covariance analyses of one way show that there is a difference between the student performance scores of post-test and groups with the pre - test scores control, so mindfulness can be said to improve students ' educational performance. In approval of this statement it can be mentioned that mindfulness helps the students to study and understand the subject by creating awareness and concentration. But this is just one aspect of how it affects educational performance. By improving students self - awareness, mindfulness helps students to recognize their weaknesses and strengths. With mindfulness training, students learn to be more present at the moment, to be alert to the inner and outer phenomena, and develop a nonjudgmental attitude with acceptance of phenomena, that leads to their academic performance development. The results 
of one-way analysis of covariance show that there is a difference between the scores of self - efficacy in posttest test students and control groups in pretest scores. Therefore, it can be said that mindfulness can improve students self - efficacy. In approval of this findings it can be said that mindfulness training teaches the students how to view their inner and outer experiences with awareness and without judgment.

If we consider self - efficacy as a kind of attitude toward our abilities, mindfulness can teach us how to pay attention to the moment without judgment about the future. And respond to the moment instead of reaction. By encouraging students to have attention and awareness of body and mind, students release their mind from mental preoccupation with anxiety about how to function in exams. In This way, students ' abilities will increase. The results of one way analysis of covariance shows that mindfulness can improve the emotional effects of students with the control of pre - test scores. Therefore, it can be said that "mindfulness" can improve the emotional effects of students. In approval of this findings it can be said that mindfulness give the students the Chance to view his environment and experiences again without a judgmental vision and to have concentration as a cure and guidance to complete awareness in order to know his environment better and accept it (Forman and Herbert, 2008).

When a person faces an emotional situation, good sense and optimism is not enough to control emotion, but an individual needs to know self - awareness in these situations and have the best cognitive function. Mindfulness can be effective in decreasing and controlling emotions due to profound mental communication with emotions. The results of one way analysis of covariance shows that there is no significant difference between the scores of pre - test scores of the groups of control and the pre-test scores, so it can be claimed that mindfulness can improve the students planning ability. In approval of these findings it can be mentioned that "mindfulness" is a sense of consciousness without judgment that helps to see and accept emotions and physical phenomena, as they happens.

Therefore, teaching it to students makes them accept their feelings and weaknesses, and acceptance of these feelings will reduce their sensitivity to the outcome of these symptoms, the ability to organize and plan the course activities on a specific and measurable basis as well as appropriate use of time to perform educational tasks and finally improve their planning. The fact that this hypothesis, according to these findings, is rejected, can be justified in this way that, since planning needs specific and technical, and needs special training, therefore, if the course of instruction and reading is not taught to the students, there will be no change in this component of academic performance, just with mindfulness. But if they have the necessary related education, their planning ability will improve. The results of one - way ANCOVA analysis showed that there is a difference between the scores of the lack of control of the outcome of the control groups with the pre - test scores. Therefore, it can be said that "mindfulness " can improve student outcome control. In approval of these findings it can be said that from mindfulness point of view, avoiding from the experiences, leads to harming. Although, experiments avoidance has a decreasing effect on unpleasant experiences, it has destructive effects in the long_ term and can lead to lack of flexibility and functional defects. Experience avoidance is formally defined as attempting to avoid or escape from thoughts. "Mindfulness enables the person to feel unpleasant experiences without trying to control them, and doing so will make the experiences look less threatening and reduce their impact on one's life.

Hence, the lack of control improves their life. Traditional and neglected patterns of negative thinking are called based on the habit to avoid problematic situations in one's life. The participants may be aware of their own negative thoughts and emotions, and can overcome the negative patterns of response to the situations, when their functions get more confident, rational, and more balanced, and thus they will step forward with more confidence in their effort to gain success. The results of the one way covariance analyses show that there is a difference between the motivation scores of students groups with the pre-test scores of control group. Therefore, it can be said that mindfulness improves the motivation of students. In approval of these findings, it can be stated that if the students find adequate recognition about their abilities and assess their positions correctly, they are more able to reinforce the motives of success, and they can continue to study with recognition of the situation in which they can increase their motivation. 
With the acquisition of this skill, significant changes are made on the individual and interpersonal indicators, so that, they gain a realistic understanding of themselves and the world around them and are empowered to control their feelings and behaviors. They also make more success in establishing effective, deep and honest relations with others. Moreover, by improving self - awareness, mental functions such as accuracy, attention, reasoning, and learning accelerate and lead to an increase in academic motivation. The results of the covariance analysis show that mindfulness training is more effective on job performance of teachers. Therefore, it can be said that the study of effectiveness and comparison of education is different on the job performance of teachers and students ' academic performance. It can be noted that considering the results obtained in the present study that shows that mindfulness therapy is more effective on teachers job performance, it is more likely that it's because teachers have higher cognitive development, and it is due to their age. Therefore, the high level of their understanding of the aforementioned issues in mindfulness sessions, and that teachers have more ability to control their thoughts, behavior, feelings and emotions, which lead to their ability in planning and discipline, can make mindfulness treatment more effective for them.

In fact, the mindfulness program is an organizer of the thoughts, feelings and behavior in which teachers are more successful due to their cognitive abilities. On the other hand, it can be stated that as far as the students are more involved in education, they are busier in education and doing homework. This could be a reason why they have been less able to take advantage of the mindfulness exercises. And due to the fact that mindfulness includes two types of formal exercises (training sessions with a coach) and informal (repetition and practice of all trained techniques of formal meetings in real life) so, teachers who have a higher age and intellectual development are expected to benefit more from non - formal exercises, and the effects of training these techniques are improved in their lives. The present study has some limitations that are useful to be mentioned in conclusion of the research findings.
Although the usefulness of using therapy techniques with behavioral therapy has been effective and increases the efficiency of the treatment, it is not available for all people because of high cost and being time consuming, as well as the unavailability of mindfulness specialists and coaches. The lack of ability to monitor practicing the tasks outside of training sessions (informal exercises) is another of the limitation of this study.

Finally, given the results of the present study which shows the effectiveness of training techniques on teachers ' underlying performance, it is suggested, managers and school administrators have to help teachers improve their job performance in a manner that affects both psychological and social contexts, and considering the situation to hold the mindfulness classes for the students before the start of the educational year. Also, based on the results of this study, which shows a higher effectiveness of training techniques on improving the emotional impact of students compared to other academic performance initiatives, school counselors, and school administrators are suggested to improve the academic performance of students who are in contact With a series of emotions such as anxiety and worrisome causing them to react in a high level, to imply this method to control the emotional effects of students. And finally, it can be suggested that, due to the unavailability of specialist trainers to teach the techniques of mindfulness, as well as the high costs of holding the courses, the teachers ' job performance is better to be the top priority of schools and educational centers, to improve the effectiveness and train the teachers who do not have the necessary quality in their underlying job performance and in case of financial and technical ability of schools and educational centers, according to the effectiveness of this method on components of educational performance, respectively, its effects on improving the emotional effects, motivation, self-efficacy, lack of outcome control, to identify the students with such problems, and train them with mindfulness techniques based on the priority of their educational problems.

\section{\# REFERENCES}

Afshari, A., Fathi, P. (2018). Investigating the relationship between sense of cohesion and mindfulness with job satisfaction: The 
mediating role of emotional intelligence, Journal of Occupational and Organizational Counseling, Issue 36, pp. 139-154. http://jcoc.sbu.ac.ir/article/view/23338

Akbari Amarghan, H., Amouzegar, Z. (2014). The Effectiveness of Mindfulness Training in Job Adaptation of Female Elementary School Teachers, Educational Research Journal, Ninth Year, Issue 39, Pp. 130-177. http://edu.bojnourdiau.ac.ir/article 519869 efca555764106f61 4df7db652ab4eabc.pdf

Akbari, M., Arjmandnia, A., Afrooz, Gh., Kamkar, K. (2017). The Effectiveness of Mindfulness Training in Self-Regulation and Academic Achievement in Students with Learning Disabilities, Journal of Behavioral Sciences Research, Vol. 15, Issue 4, Pp. 518-525 https://www.magiran.com/paper/1809288

Arab Faizabadi, Sh., Karimzadeh, S., Nastizaee, N. (2014). Predicting teachers' job performance based on Walton's quality of work life model, Educational Management Innovations, Vol. 10, Issue 1 , Pp. 50-63. https://jmte.riau.ac.ir/article_250.html

Baginski, A. (2015). Attention regulation, emotion regulation, and cognitive flexibility as mediators of the relationship between mindfulness and academic achievement in high school students. Submitted in partial fulfillment of the requirements for the degree of specialist in school psychology in the graduate school, Eastern Illinois University Charleston, Illinois. Google Scholar

Baldauf, A., and Cravens, D. W. (2002). The effect of moderators on the salesperson behavior performance and salesperson outcome performance and sales organization effectiveness. European Journal of Marketing, 36, 1367-1388. https://doi.org/10.1108/03090560210445227 Google Scholar

Brandy, R., Maynard, G., Michael, R., Solis, H., and Veronica Miller, S. (2014). Mindfulness-based interventions for improving academic achievement, behavior and socio-emotional functioning of primary and secondary students: A systematic review. San Francisco, CA, US: Josser-Bass. Google Scholar

Brian, D. (2011). The role of mindfulness in academic stress, selfefficacy, and achievement in college students. Masters Theses Student Theses and Publications, Eastern Illinois University. Google Scholar

Britton, W. B. (2015). A randomized controlled pilot trial of classroom-based mindfulness meditation compared to an active control condition in sixth-grade children. Journal of School Psychology, 52(3), 263-278. https://doi.org/10.1016/j.jsp.2014.03.002 Google Scholar

Brown, K. W., Creswell, J. D., and Ryan, R. M. (2015). The evolution of mindfulness research. New York, NY: Guilford Press. Google $\underline{\text { Scholar }}$

Brown, V., and Oslan, K.(2015). The mindful school leader: Practices to transform your leadership and school. Thousand Oaks, CA: Corwin.

Day, M. A., and Thorn, B. E. (2017). Mindfulness-based cognitive therapy for headache pain: An evaluation of the long-term maintenance of effects. Complementary Therapies in Medicine, 33, 94-98. https://doi.org/10.1016/j.ctim.2017.06.009 Google Scholar

Forman, E. M., and Herbert, J. D. (2008). New directions in cognitive behavior therapy: Acceptance based therapies. Hoboken, NJ: Wiley. Google Scholar

Hashemian, S. N. (2013). The causal relationship between achievement goals and academic performance mediated by negative academic emotions and academic procrastination in MA students of Shahid Chamran University of Ahvaz, MSc thesis in Educational Psychology, Shahid Chamran University of Ahvaz. https://elib.scu.ac.ir/faces/search/bibliographic/biblioFullView. jspx? afPfm=3hyhoopmn
Izadi, R., Askari, K., Neshat Doost, T., Abedi, M. R. (2014). The Effect of Acceptance and Commitment Therapy on the Frequency and Severity of Symptoms of Obsessive Compulsive Disorder, Zahedan Journal of Research in Medical Sciences, Vol. 1, Issue 33, Pp. 20-26. https://sites.kowsarpub.com/zjrms/articles/93208.html

Janaabadi, H., Pillechi, L., Salm Abadi, M., Tirani Rad, A. (2016). The Effectiveness of Mindfulness Skills Training in Job Stress and Psychological Well-Being of Female Teachers, Journal of Health Users, Vol. 13, Issue 6, Pp. 58-69. http://ioh.iums.ac.ir/browse.php?a id =1574\&slc lang=fa\&sid= $\underline{1}$ \&printcase $=1 \&$ hbnr $=1 \& \mathrm{hmb}=1$

Kabat-Zinn, J., Massion, A. O., Kristeller, J., Peterson, L. G., Fletcher, K. E., Pbert, L., Lenderking, W. R., and Santorelli, S. F. (2007). Effectiveness of a meditation based stress reduction program in the treatment of anxiety disorders. Am J Psychiatry, 149, 936-943. https://doi.org/10.1176/ajp.149.7.936 Google Scholar

Kaviani, H., Hatami, N., Shafiabadi, A. (2008). The effect of mindfulness-based cognitive therapy on quality of life in depressed individuals, Cognitive Science News, Vol. 10, Issue 4, Pp. 39-48. http://icssjournal.ir/article-1-466-en.pdf

Khorsandifard, M., Fahim Dovin, H., Anjam Shua, M. R. (2016). The Effect of Verbal Neural Planning on Job Motivation and Job Performance of Physical Education Teachers in Mashhad, Organizational Behavior Management Studies on Sport, Vol. 9, Issue 9, 9 P. 31-38. http://fmss.journals.pnu.ac.ir/article 2602.html

King, E., and Haar, J. (2017). Mindfulness and job performance: A study of Australian leaders. Asian Pacific Journal of Human Resources, 55(3), 298-319. https://doi.org/10.1111/17447941.12143 Google Scholar

Leland, M. (2015). Mindfulness and student success. Journal of Adult Education, 44(1), 19-24. https://www.mpaea.org/?page=publications Google Scholar

Lu, S., Huang, C., and Rios, J. (2017). Mindfulness and academic performance: An example of mi-grant children in China. Children and Youth Services Review, 82, 53-59. https://doi.org/10.1016/j.childyouth.2017.09.008 Google Scholar

Luberto, C. M. (2014). Mindfulness skills and emotion regulation: The mediating role of coping self-efficacy. Mindfulness, 5(4), 373-380. Google Scholar

Maloney, J. E. (2016). A Mindfulness-based social and emotional learning curriculum for school-aged children: The Mind UP Program. New York, NY, US: Springer-Verilog Publishing. Google Scholar

Mesmer-Magnus, J., Manapragada, A., Viswesvaran, C., and Allen, J. W. (2017). Trait mindfulness at work: A meta-analysis of the personal and professional correlates of trait mindfulness. Human Performance, 30(2-3), 79-98. https://doi.org/10.1080/08959285.2017.1307842 Google Scholar

Mettler, J., Carsley, D., Joly, M., and Heath, N. L. (2017). Dispositional mindfulness and adjustment to university. Journal of College Student Retention: Research, Theory and Practice, 21, 38-52. https://doi.org/10.1177/1521025116688905 Google Scholar

Napoli, M. (2013). Mindfulness training for teachers: A pilot program. Complementary Health Practice Review, 9(1), 201-211. https://doi.org/10.1177/1076167503253435 Google Scholar

Pham, L. B., and Taylor, S. E. (1999). From thought to action: Effects of process-versus outcome-based mental simulations on performance. Society for Personality and Social Psychology, 25(2), 250-260. https://doi.org/10.1177/0146167299025002010 Google Scholar 
Potek, R. (2012). Mindfulness as a school-based prevention program and its effect on adolescent stress, anxiety and emotion regulation. Contem Fam Ther, 23(3), 259-308. Google Scholar

Puriarizi, M., Tohidi, A., Khezri Moghadam, N. (20187). The effect of mindfulness on academic achievement and academic adjustment: The mediating role of academic self-concept, Journal of Positive Psychology Research, Issue 3, Pp. 29-44. 10.22108/PPLS.2018.111795.1464

Rastgoo, N., Herfedoost, M., Kheirju, I. (2016). The Effectiveness of Group Mindfulness Training in Job Burnout, Job Satisfaction and Some Teachers' Psychopathology Syndrome, Journal of Cognitive Strategies in Learning, Vol. 4, Issue 7, Pp. 179-198. 10.22084/J.PSYCHOGY.2017.1660

Reb, J. (2018). Leader mindfulness and employee performance: A sequential mediation model of LMX quality, interpersonal justice, and employee stress. Journal of Business Ethics, 18, 1-19. Google Scholar

Seif, A. A. (2013). Modern Breeding Psychology: The Psychology of Learning and Education, Tehran: Doran Publications. Link

Sharf, R. S. (2009). Applying career development theory to counseling. Engage Learning Academic Resource Center, 1, 12-25. Google Scholar
Spinhoven, P., Huijbers, M. J., Ormel, J., and Speckens, A. E. M. (2017). Improvement of mindful-ness skills during mindfulness-based cognitive therapy predicts long-term reductions of neuroticism in persons with recurrent depression in remission. Journal of Affective Disorders, 213, 112117. https://doi.org/10.1016/j.jad.2017.02.011 Google Scholar

Tuckey, M. R., Sonnentag, S., and Bryan, J. (2018). Are state mindfulness and state work engagement related during the workday? Work and Stress, 10, 1-16. https://doi.org/10.1080/02678373.2017.1420707 Google Scholar

Zahrakar, K. (2005). Investigating the Relationship between Different Dimensions of Family Functioning and Academic Performance of High School Students in Lorestan Province. MSc Thesis in Psychology, University of Tehran.

Zarei, S., Arshad Hosseini, A. S. (2018). The Effectiveness of Mindfulness-Based Therapy in Occupational Stress and Job Selfefficacy of Physical Education Trainers, Sport Psychology Studies, Vol. 7, Issue 26, Pp. 1-20. Google Scholar

Zargar, F., Mohammadi, A., Omidi, A., Bagherian Sararoodi, R. (2012). Third Wave of Behavior Therapy with Emphasis on AcceptanceBased Therapy, Journal of Behavioral Sciences Research, Vol. 10, Issue 5, Pp. 383-390. Link 